\title{
BMJ Open Predictors of health insurance enrolment and wealth-related inequality in Nepal: evidence from Multiple Indicator Cluster Survey (MICS) 2019
}

\author{
Umesh Prasad Bhusal (D) , ${ }^{1}$ Vishnu Prasad Sapkota (D) ${ }^{2}$
}

To cite: Bhusal UP, Sapkota VP Predictors of health insurance enrolment and wealth-related inequality in Nepal: evidence from Multiple Indicator Cluster Survey (MICS) 2019. BMJ Open 2021;11:e050922. doi:10.1136/ bmjopen-2021-050922

- Prepublication history for this paper is available online. To view these files, please visit the journal online (http://dx.doi. org/10.1136/bmjopen-2021050922).

Received 04 March 2021 Accepted 28 October 2021

Check for updates

(c) Author(s) (or their employer(s)) 2021. Re-use permitted under CC BY-NC. No commercial re-use. See rights and permissions. Published by BMJ.

${ }^{1}$ Public Health and Social Protection Professional, Kathmandu, Nepal

${ }^{2}$ Department of Economics, Nepal Commerce Campus, Tribhuvan University, Kathmandu, Nepal

Correspondence to Vishnu Prasad Sapkota; vishnu.sapkota@ncc.tu.edu.np

\section{ABSTRACT}

Objectives We analysed predictors of health insurance enrolment in Nepal, measured wealth-related inequality and decomposed inequality into its contributing factors. Design Cross-sectional study.

Setting We used nationally representative data based on Nepal Multiple Indicator Cluster Survey 2019. Out of 10958 households included in this study, $6.95 \%$ households were enroled in at least one health insurance scheme.

Primary outcome measures health insurance (of any type) enrolment.

Results Households were more likely to have health insurance membership when household head have higher secondary education or above compared with households without formal education (adjusted OR 1.87; 95\% Cl: 1.32 to 2.64)). Households with mass media exposure were nearly three times more likely to get enroled into the schemes compared with their counterparts (adjusted OR 2.96; $95 \% \mathrm{Cl} 2.03$ to 4.31). Hindus had greater odds of being enroled (adjusted OR 1.82; 95\% Cl 1.20 to 2.77) compared with non-Hindus. Dalits were less likely to get enroled compared with Brahmin, Chhetri and Madhesi (adjusted OR 0.66; 95\% Cl 0.47 to 0.94). Households from province 2, Bagmati and Sudurpaschim were less likely to have membership compared with households from province 1. Households from Richer and Richest wealth quintiles were more than two times more likely to have health insurance membership compared with households from the poorest wealth quintile. A positive concentration index $0.25(95 \% \mathrm{Cl} 0.21$ to $0.30 ; \mathrm{p}<0.001)$ indicated disproportionately higher health insurance enrolment among wealthy households.

Conclusions Education of household head, exposure to mass media, religious and ethnic background, geographical location (province) and wealth status were key predictors of health insurance enrolment in Nepal. There was a significant wealth-related inequality in health insurance affiliation. The study recommends regular monitoring of inequality in health insurance enrolment across demographic and socioeconomic groups to ensure progress towards Universal Health Coverage.

\section{INTRODUCTION}

Many countries are pursuing Universal Health Coverage (UHC) globally-one of the
Strengths and limitations of this study

- This is the first study using nationally representative household survey to identify determinants associated with health insurance enrolment in Nepal.

- This study provides a baseline scenario of health insurance enrolment in Nepal and presents existing disparities across socioeconomic groups.

- The analysis was done after accounting for complex survey design such as cluster effect and sample weight.

- A relative measure of inequality using concentration index was used to measure wealth-related inequality in health insurance enrolment.

targets of Sustainable Development Goals to be achieved by $2030 .{ }^{1} \mathrm{UHC}$ is about people having access to the needed health services without financial hardship. ${ }^{2}$ It includes the full spectrum of essential health services, ranging from health promotion to prevention, treatment, rehabilitation and palliative care. More specifically, notions inherent in the UHC are: (1) equity in access to and use of services, meaning that the health services should be available based on need rather than the ability to pay; (2) health services should be of quality to improve the health status of those getting services and (3) cost of using health services should not put users at financial risk. ${ }^{2} \mathrm{WHO}$ has recognised health system strengthening, including the health financing reform, as one of the prerequisites to make progress towards UHC. $^{2}$ Out-ofpocket (OOP) payments at service point pose a financial barrier to access needed health services for poor. For rich, unpredicted high cost puts family in financial hardship. So, WHO recommends pooling arrangements, the process of accumulating prepaid healthcare revenues on behalf of a population, to be established in countries so that the financial risks associated with health uncertainty 
can be spread across population. ${ }^{2}{ }^{3}$ Especially, after the policy resolution of the World Health Assembly in May 2005 and World Health Report 2010, WHO recommends member states to adopt health insurance as one of the key strategies to bring about reforms in how health resources are generated and used for achieving UHC through the sustainable health financing system. ${ }^{24}$

In recent years, an increasing number of low-income and middle-income countries (LMICs) such as Ghana, the Philippines, Vietnam, Indonesia is moving away from the 'user fees' to risk pooling arrangement, such as health insurance, with an objective to reduce the reliance on OOP payment and to improve equity in the provision of health care. ${ }^{5}$ The longer-term goal is to establish a mechanism to ensure access to needed quality healthcare for all at an affordable price as envisioned by UHC. ${ }^{6-8}$ Still, at present about half of the world population is deprived of the health services they need and about 100 million people each year are falling into the trap of extreme poverty owing to the burden of OOP spending on health. ${ }^{9}$

In Nepal, the largest share of health expenditure was borne by households, responsible for $57.4 \%$ of the current health expenditure via direct OOP payment in 2016/2017. ${ }^{10}$ According to a recent estimate, $10.7 \%$ (at 10\% threshold) of households and 2.4\% (at 25\% threshold) of households from Nepal experienced catastrophic expenditure on health. ${ }^{11}$ Catastrophic expenditure on health is an indicator of financial protection against OOP used to monitor progress towards UHC. It measures the proportion of the population with OOP health payments that exceeds, for instance, $10 \%$ or $25 \%$ of their total consumption. ${ }^{11}$ Further, $1.7 \%$ of the Nepalese were pushed below the poverty line of US\$1.9 international dollar purchasing power parity due to direct OOP payment. ${ }^{11}$ To address this challenge in health financing and to accelerate progress towards UHC, the government of Nepal (GoN) has initiated various social health protection schemes, such as health insurance and social security schemes. Health insurance is a relatively new concept for Nepal, except for scattered community-based health insurance schemes and small-scale private health insurance schemes. ${ }^{12}{ }^{13}$ In 2016/2017, health insurance was accountable for just $0.8 \%$ of CHE; $0.6 \%$ born by voluntary health insurance schemes and $0.2 \%$ by compulsory contributory health insurance schemes. ${ }^{10}$

Since 2016, GoN Health Insurance Board (HIB) has implemented National Health Insurance (NHI) starting from three pilot districts: Kailali, Baglung and Ilam. By April 2021, the scheme has been scaled up in 75 districts, out of total 77 , in a phase-wise manner. Though the health insurance act 2017 declares NHI mandatory for both the formal and informal sector, it is implemented currently as a voluntary scheme with a focus on the informal sector and targeted population. Annual premium of targeted population groups such as ultrapoor households; elderly above 70 years; households having a member suffering from specified diseases (leprosy/HIV/multidrug-resistant tuberculosis) or person with an extreme disability is fully subsidised by the government. Whereas, annual premium of Female Community Health Volunteers (FCHVs) is partially (50\%) subsidised. More than 50000 FCHVs are working at the community level in Nepal mainly responsible for promoting healthy behaviours and uptake of health and social protection (such as NHI) services. ${ }^{14}$ Ultrapoor households are identified by national level household consumption or expenditure survey conducted by Ministry of Land Management, Cooperatives and Poverty Alleviation using proxy means test. ${ }^{15} 16$ NHI covers outpatient services, inpatient services, diagnostics services and drugs from both public (first point of contact) and private healthcare facilities. A family of five members is insured for healthcare services up to NPR 100 000 per year for an annual premium of NPR 3500, with no copayment.

Similarly, the GoN has launched social security schemes to the formal sector (to be scaled up to informal sector as well in future) from 2017 through Social Security Fund (SSF). The SSF offers four different security schemes to the enroled people: (1) medical treatment, health and maternity security scheme; (2) accident and disability security scheme; (3) dependent family security scheme and (4) old age security scheme (60 years and above). Among the four schemes of SSF, the first and second are health insurance schemes. Since both the schemes are still in the expansion stage, only around $11 \%$ of the total population (about 30 million) is covered by $\mathrm{NHI},{ }^{17}$ more than one-third of the enroled households are subsidised by the government. ${ }^{18}$ Likewise, just under 0.2 million individuals from formal private sector are enroled with the SSF schemes. ${ }^{19}$

In this study, we have examined the association between socioeconomic and demographic factors at the household level with the decision to get enroled in health insurance in Nepal. We have also assessed whether health insurance enrolment is equitable across different wealth quintiles. This will help identify population subgroups at risk of being excluded from pooling arrangements; key for achieving equity and universality in health. It is also of policy relevance to analyse the coverage from an equity perspective since the GoN has made provisions to subsidise the enrolment of ultrapoor households into NHI. This study will provide a baseline scenario of health insurance enrolment (of any type) in Nepal and potentially help policymakers and planners design health insurance coverage expansion strategy for the recently launched NHI and SSF schemes. Studies of similar nature are available from Nepal and other LMICs, but this is the first of its kind from Nepal using the nationally representative household survey.

\section{METHOD}

\section{Data source and sampling design}

This study is based on data from Multiple Indicator Cluster Surveys (MICS) 2019 conducted in Nepal by the Central Bureau of Statistics. The technical and financial support 
for this household survey was provided by UNICEF. The survey, started in the mid-1990s and now implemented in more than 100 countries, aims to monitor the situation of women and children by capturing the information on health, education, social protection, environment along with the socioeconomic and geographical characteristics including household characteristics, wealth, area, religion, caste/ethnicity.

MICS is a cross-sectional representative household survey that use multistage probability designs to establish a representative sample of households at the national and subnational levels (eg, province). Within each province, the urban and rural areas were defined as the main sampling strata and the sample of households was selected in two stages. At the first stage, a specified number of census Enumeration Areas (EA) was proportionally selected within each stratum using systematic random sampling. At the second stage, the household listing was carried out within the selected census EA, identifying the households with and without children under 5 years. In total, 25 households with and without children under 5 were selected in each census EA through a systematic random sampling method. For MICS 2019, a total of 512 EAs and 12800 households were selected. The data collection period spanned from May to November 2019. Details of the MICS design and methodology are available elsewhere. $^{20} 21$

\section{Study participants}

The survey conducted face-to-face interviews using standardised questionnaires with household respondent (for information on household characteristics), women and men aged 15-49 years (for present and retrospective information on themselves), and mothers (or caregivers) (for information on behalf of children under 18 years) ${ }^{20}$ For this study, the data from women and men aged 15-49 years regarding their response to the questions related to health insurance, their socioeconomic and household characteristics were taken. The data were analysed at household level.

\section{Study variables}

Men and women responding 'yes' to the question 'Are you covered by any health insurance?' were taken as being enroled into health insurance scheme. Respondents covered by health insurance were enroled in one of the following types of health insurance: (1) communitybased health insurance, (2) health insurance provided by employer, (3) health insurance provided by social security scheme, (4) private health insurance and (5) others. If any member of household was enroled in one of the above-mentioned schemes, the household was considered as enroled in health insurance scheme. The independent variables included in this study were socioeconomic, demographic and geographical variables, and household characteristics.

Geographical area was divided into rural and urban. Family size was categorised into three groups: family with five or fewer members; family with 6-10 members; and family with eleven or more members. Households with under- 5 children were categorised into two groups based on the presence or absence of children under 5 years. Education of household head was categorised into four broad groups: without formal education; with primary education (grades 1-5); with secondary education (grades 6-10); and higher secondary education and above (grade 11 and above). Sex of household head was categorised as female and male. Religion was broadly categorised as Hindu and non-Hindu. Regarding ethnicity, more than 100 castes recorded during the survey were reclassified into broad caste/ethnic groups based on the classification done in Population Monograph of Nepal 2014. ${ }^{22}$ Brahmin, Chhetri and Madhesi were classified in one group; Janajati from mountain, hill, and terai and Newer were classified in the second group; Dalits from mountain hill and terai and Muslims were classified in the third group; rest (Marwadi, Bangali, etc) were classified as others.

Variables for which data were household member specific were aggregated at household level: Media exposure of the household was categorised into two groups. Households were taken as exposed to media if any household member either listened to radio or watched television (TV) or read magazine at least less than once in a week to almost every day. According to age composition of members, households were categorised into three mutually exclusive groups: households with only adults (20-59 years); household with adults (20-59 years) and children and/or adolescents; household with adults and older person (or multigenerational). In addition to these factors, health-related behaviours like consumption of bads is likely to affect the health insurance enrolment explained using adverse selection models in voluntary schemes. ${ }^{23}{ }^{24} \mathrm{We}$, therefore, included alcohol and tobacco consumption in our model. Alcohol consumption was classified as 'yes' if at least one member in the household had alcohol in past month and 'no' otherwise. Similarly, smoking was classified as 'yes' if at least one member in the household was current smoker at the time of interview and 'no' otherwise.

Other variables included in the study were functional disability (yes/no) and wealth index quintile.

\section{Method of analysis}

The frequencies and percentages were used to describe characteristics of the study sample. We used logistic regression model shown in equation 1 to assess association between independent variables and health insurance enrolment.

$$
\operatorname{Prob}(Y=1 \mid X)=\varnothing(X \beta)
$$

Where, $\operatorname{Prob}(Y=1 \mid X)$ indicates the probability that any member in the household is enroled in one of the insurance schemes conditional on household characteristics $(X), X$ is a matrix where column are variables that are likely to be associated with insurance enrolment, and 
$\varnothing$ is the cumulative distribution function of the standard logistic distribution. The parameter vector $\beta$ were estimated by maximum likelihood technique. Our objective was to explore the correlates of insurance enrolment rather than causality, therefore endogeneity was not a concern here. ${ }^{25}$ Variance inflation factors (VIFs) was used to examine multicollinearity among covariates before performing regression analysis. All covariates had VIFs less than or equal to $2.5 .^{26}$ Complex survey design was declared to account for sample weight, primary sampling unit (EA) and strata before conducting analysis.

We estimated two models: unadjusted and adjusted for bivariate and multivariate logistic regression, respectively. In unadjusted model, we included the independent variable one at a time. For the adjusted one, we build the model with the list of variables based on literature review of empirical studies. ${ }^{72-34}$ We retained all the variables in the final model despite their level of significance since these were significant predictors of insurance enrolment in some of the studies. STATA statistical software V.16 ${ }^{35}$ was used for the analysis.

\section{Inequality measurement}

Inequality in health refers to the systematic differences in health across population subgroups based on underlying socioeconomic, demographic, political and geographical factors and modifiable through appropriate intervention. ${ }^{36-38}$ The most popular approaches to quantify living standard are income and consumption measures. ${ }^{39}$ However, in the absence of such measures, we used wealth index as proxy of living standard variable at household level and used it to measure inequality. The survey used following household characteristics to create wealth index score: electricity, energy used for cooking, internet access, the main materials of flooring, roof and exterior walls, the number of rooms used for sleeping, ownership of assets and status of sanitation and hygiene. ${ }^{20}$ The concentration curve and index for health insurance enrolment were produced in their relative formulation, with no correction. The concentration index was measured as twice the area between the concentration curve and the line of equality (the $45^{\circ}$ line) and was calculated adopting the procedure described by O'Donnell et a ${ }^{39}$ using 'convenient covariance' equation 2 shown below.

$$
C=\frac{2}{\mu} \operatorname{cov}(h, r)
$$

Here $h$ is the health sector variable, $\mu$ is its mean, and $r=i / N$ is the fractional rank of individual $i$ in the living standards distribution, with $i=1$ for the poorest and $i=N$ for the richest.

The concentration curves were prepared using the ggplot 2 package ${ }^{40}$ in R software for statistical computing. ${ }^{41}$

\section{Decomposition of the concentration index}

The concentration index computed using equation 2 was decomposed into the contribution of factors at household level. It is obtained using methodology described by O'Donnel et $a l .{ }^{39}$ The regression model used in decomposition with $k$ household specific characteristics $\left(x_{i}\right)$ is given by equation 3 .

$$
h=\alpha+\sum_{i=1}^{k} \beta_{i} x_{i}+\varepsilon
$$

The decomposition equation for Concentration Index (C) can be written as equation 4 .

$$
C=\sum_{i=1}^{k} \frac{\beta_{i} \bar{x}_{i}}{\mu} C_{i}+\frac{G C_{\varepsilon}}{\mu}
$$

Where, $\bar{x}_{i}$ is the mean of $x_{i}, C_{i}$ is the concentration index attributed to $x_{i}$. The first component in right hand side of the equation 4 is the linear sum of $k$ terms related to the variables included in the decomposition analysis. Rest of the concentration index not explained by variables $\left(x_{i}\right)$ is second component $\left(G C_{\varepsilon} / \mu\right.$ that captures the generalised concentration index for the error term $(\varepsilon)$. In the decomposition analysis, we started with policy-relevant characteristics that explain insurance enrolment in unadjusted regression model. Socioeconomic and geographical variables were finally included to explain the observed inequality measured by concentration index.

\section{Patient and public involvement}

Patient and public were not involved in this study.

\section{RESULTS}

\section{Descriptive summary}

Among 10958 households included in this analysis, $6.95 \%$ of households were enroled in health insurance. Table 1 presents socioeconomic, demographic and lifestyle behaviour-related characteristics of households included in this analysis. Among the variables; household age composition, area of residence, education of household head, media exposure, religion, ethnicity, province and wealth index quintile had $\mathrm{p}<0.05$ generated from the $\chi^{2}$ test. About $69 \%$ of households included in this study were from urban area. More households $(7.9 \%)$ from urban area were enroled in health insurance compared with rural area $(4.9 \%)$. About one-third of household head had no formal education and another one-third of household head had a secondary level education. One in every five household head had primary education and the rest $(14.4 \%)$ had higher secondary or college education. Greater percentage of households with their head having higher secondary or college education were enroled in health insurance $(13 \%)$, followed by secondary $(7.9 \%)$, primary $(5.6 \%)$ and no formal education $(4.2 \%)$. More than $80 \%$ of the households had at least one person exposed to mass media (radio or TV or magazine). Households having members exposed to mass media had higher percentage of health insurance enrolment $(8 \%)$ compared with the ones without exposure $(1.9 \%)$. About $85 \%$ of households were Hindus. Similarly, majority of households were Brahmin or Chhetri or Madhesi $(44.3 \%)$, followed by Janajati or Newar $(38.9 \%)$ and Dalits (14.3\%). Higher percentage of Hindus $(7.5 \%)$ and 
Table 1 Socioeconomic, demographic and lifestyle behaviour-related characteristics of households by health insurance (of any type) status (\%)

\begin{tabular}{|c|c|c|c|c|}
\hline Variables & $\begin{array}{l}\text { Weighted } \\
\text { frequency (\%) }\end{array}$ & $\begin{array}{l}\text { Insured } \\
\text { households }\end{array}$ & $\begin{array}{l}\text { Non-insured } \\
\text { households }\end{array}$ & $\begin{array}{l}\text { P value for } \chi^{2} \\
\text { test }\end{array}$ \\
\hline \multicolumn{5}{|l|}{ Household age composition } \\
\hline Only adults (20-59 years) & $1391(12.7)$ & 8.5 & 91.5 & 0.027 \\
\hline Adults (20-59 years) and children and/or adolescents & $8203(74.9)$ & 6.5 & 93.5 & \\
\hline Adults and older person (or multigenerational) & $1364(12.5)$ & 8.2 & 91.8 & \\
\hline \multicolumn{5}{|l|}{ Sex of household head } \\
\hline Female & $3175(29)$ & 6.7 & 93.3 & 0.640 \\
\hline Male & $7783(71)$ & 7.0 & 93.0 & \\
\hline \multicolumn{5}{|l|}{ Area of residence } \\
\hline Rural & $3389(30.9)$ & 4.9 & 95.1 & $<0.001$ \\
\hline Urban & $7568(69.1)$ & 7.9 & 92.1 & \\
\hline \multicolumn{5}{|l|}{ Family size } \\
\hline $1-5$ & $8181(74.7)$ & 7.1 & 92.9 & 0.523 \\
\hline $6-10$ & $2622(23.9)$ & 6.4 & 93.6 & \\
\hline $11+$ & $154(1.4)$ & 6.3 & 93.7 & \\
\hline \multicolumn{5}{|l|}{ Household with under 5 children } \\
\hline No & $7043(64.3)$ & 7.3 & 92.7 & 0.181 \\
\hline Yes & $3915(35.7)$ & 6.3 & 93.7 & \\
\hline \multicolumn{5}{|l|}{ Education of household head } \\
\hline No (formal) education & $3583(32.7)$ & 4.2 & 95.8 & $<0.001$ \\
\hline Primary (grade 1-5) & $2213(20.2)$ & 5.6 & 94.4 & \\
\hline Secondary (grade 6-10) & $3580(32.7)$ & 7.9 & 92.1 & \\
\hline Higher secondary and above (grade11 and above) & $1580(14.4)$ & 13.0 & 87.0 & \\
\hline \multicolumn{5}{|l|}{ Media exposure } \\
\hline No exposure & $1839(16.8)$ & 1.9 & 98.1 & $<0.001$ \\
\hline Exposure & 9119 (83.2) & 8.0 & 92.0 & \\
\hline \multicolumn{5}{|l|}{ Religion } \\
\hline Non-Hindu & $1622(14.8)$ & 3.8 & 96.2 & $<0.001$ \\
\hline Hindu & $9336(85.2)$ & 7.5 & 92.5 & \\
\hline \multicolumn{5}{|l|}{ Ethnic group } \\
\hline Brahmin, Chhetri and Madhesi & $4859(44.3)$ & 8.3 & 91.7 & $<0.001$ \\
\hline Janajati and Newar (Mountain Hill and Terai) & $4260(38.9)$ & 6.5 & 93.5 & \\
\hline Dalit (Mountain Hill and Terai) and Muslim & $1572(14.3)$ & 4.1 & 95.9 & \\
\hline Others (Marwadi, Bangali, etc) & $265(2.4)$ & 6.5 & 93.5 & \\
\hline \multicolumn{5}{|l|}{ Alcohol consumption } \\
\hline No & 8058 (73.5) & 6.9 & 93.1 & 0.917 \\
\hline Yes & $2900(26.5)$ & 7.0 & 93.0 & \\
\hline \multicolumn{5}{|l|}{ Current smoker } \\
\hline No & $9313(85)$ & 6.8 & 93.2 & 0.260 \\
\hline Yes & $1645(15)$ & 7.8 & 92.2 & \\
\hline \multicolumn{5}{|l|}{ Functional disability } \\
\hline No & $10621(96.9)$ & 6.9 & 93.1 & 0.208 \\
\hline Yes & $337(3.1)$ & 9.0 & 91.0 & \\
\hline
\end{tabular}


Table 1 Continued

\begin{tabular}{lcccc}
\hline Variables & $\begin{array}{l}\text { Weighted } \\
\text { frequency (\%) }\end{array}$ & $\begin{array}{l}\text { Insured } \\
\text { households }\end{array}$ & $\begin{array}{l}\text { Non-insured } \\
\text { households }\end{array}$ & $\begin{array}{l}\text { P value for } \chi^{2} \\
\text { test }\end{array}$ \\
\hline Province 1 & $1892(17.3)$ & 9.4 & 90.6 & $<0.001$ \\
\hline Province 2 & $1843(16.8)$ & 2.0 & 98.0 & \\
\hline Bagmati province & $2827(25.8)$ & 7.6 & 92.4 & \\
\hline Gandaki province & $986(9.0)$ & 10.1 & 89.9 & \\
\hline Lumbini province & $1929(17.6)$ & 8.2 & 91.8 & \\
\hline Karnali province & $596(5.4)$ & 9.3 & 90.7 & \\
Sudurpaschim province & $885(8.1)$ & 2.3 & 97.7 & \\
Wealth index quintile & & & & \\
\hline Poorest & $1997(18.2)$ & 4.1 & 95.9 & $<0.001$ \\
\hline Second & $2087(19.0)$ & 3.4 & 96.6 & \\
\hline Middle & $2106(19.2)$ & 5.7 & 94.3 & \\
\hline Richer & $2288(20.9)$ & 9.1 & 90.9 & \\
\hline Richest & $2480(22.6)$ & 11.3 & 88.7 & \\
\hline Total & 10958 & 762 & 10196 & \\
\hline
\end{tabular}

$\mathrm{N}=10958$.

upper caste (Brahmin or Chhetri or Madhesi and Janajati or Newar) were enroled in health insurance compared with non-Hindus (3.8\%) and Dalits/Muslim (2.4\%). Higher percentage of the households were from Bagmati province $(25.8 \%)$, followed by Lumbini $(17.6 \%)$, province $1(17.3 \%)$, province 2 (16.8\%), Gandaki (9.0\%), Sudurpaschim $(8.1 \%)$ and Karnali (5.4\%). Households from Gandaki province had higher percentage of health insurance coverage $(10.1 \%)$, followed by province 1 $(9.4 \%)$, Karnali province $(9.3 \%)$, Lumbini province $(8.2 \%)$, Bagmati province $(7.6 \%)$ and Sudurpaschim province $(2.3 \%)$. All the households included in the analysis were nearly equally distributed into different wealth index quintiles; $18.2 \%$ in the poorest quintile to $22.6 \%$ in the richest quintile. Households from richest quintile had higher health insurance enrolment (11.3\%), followed by richer quintile $(9.1 \%)$, middle quintile $(5.7 \%)$, poorest quintile $(4.1 \%)$ and poorer quintile $(3.4 \%)$.

\section{Results from the regression model}

The results from bivariate and multivariate regression analysis are presented in table 2 in terms of OR, corresponding CI and $\mathrm{p}$ value.

Households with adults (20-59 years) and children and/or adolescents had lower odds of getting enroled in health insurance schemes (OR $0.75 ; 95 \%$ CI 0.58 to 0.98 ) compared with households with only adults. However, this relation was statistically not significant in multivariate regression models. Similarly, sex of household head, size of the family, households with under five children, households having member with functional disability and households with at least one member that consumes alcohol did not show statistically significant association with the decision to get enroled into health insurance schemes in both bivariate and multivariate analysis. Households from urban area had higher odds of getting the health insurance membership (OR 1.64; 95\% CI 1.23 to 2.20) compared with the ones from rural area in bivariate analysis, however, such relation was not statistically significant in multivariate analysis.

Education of household head, exposure to media, religion, ethnicity, currently smoking, province and wealth index quintile were found to be important predictors of enrolment into the health insurance schemes. Households with educated head (higher secondary and above) were more likely to have health insurance membership compared with the households without formally educated head (adjusted OR 1.87; 95\% CI 1.32 to 2.64). Similarly, households with members exposed to mass media (radio or TV or magazine) were nearly three times more likely to get enroled into the schemes compared with the counterparts (adjusted OR 2.96; 95\% CI 2.03 to 4.31). In terms of religion, Hindus had greater odds of being enroled into the schemes (adjusted OR 1.82; 95\% CI 1.20 to 2.77) compared with non-Hindus. Similarly, ethnicity also played an important role in household's decision to enrol into the health insurance schemes since Dalits were less likely to join the schemes in comparison to the households belonging to upper caste such as Brahmin, Chhetri and Madhesi (adjusted OR 0.66; 95\% CI 0.47 to 0.94). Households with currently smoking member were slightly more likely to have health insurance membership compared with the reference category (adjusted OR 1.42; $95 \%$ CI 1.04 to 1.94 ).

In terms of province, households belonging to province 2, Bagmati province and Sudurpaschim province had lower odds of being enroled in health insurance 
Table 2 Determinants of health insurance (of any type) enrolment in Nepal in 2019, N=10958

\begin{tabular}{|c|c|c|}
\hline \multirow[b]{2}{*}{ Variables } & \multicolumn{2}{|l|}{ OR $(95 \% \mathrm{Cl})$} \\
\hline & Unadjusted model & Adjusted model \\
\hline \multicolumn{3}{|l|}{ Household age composition } \\
\hline Households with adults (20-59 years) and children and/or adolescents & $0.75(0.58 \text { to } 0.98)^{*}$ & $0.92(0.70$ to 1.21$)$ \\
\hline Households with adults with older person or multigenerational & $0.96(0.70$ to 1.32$)$ & $1.17(0.82$ to 1.66$)$ \\
\hline Female & Ref. & Ref. \\
\hline Male & $1.05(0.85$ to 1.31$)$ & $1.13(0.89$ to 1.43$)$ \\
\hline \multicolumn{3}{|l|}{ Area of residence } \\
\hline Rural & Ref. & Ref. \\
\hline Urban & $1.64(1.23 \text { to } 2.20)^{\star \star \star}$ & $1.08(0.77$ to 1.5$)$ \\
\hline $11+$ & 0.87 (0.40 to 1.87$)$ & $1.09(0.47$ to 2.52$)$ \\
\hline \multicolumn{3}{|l|}{ Household with under-five children } \\
\hline No & Ref. & Ref. \\
\hline Yes & 0.85 (0.68 to 1.08$)$ & $1.00(0.79$ to 1.26$)$ \\
\hline \multicolumn{3}{|l|}{ Education of household head } \\
\hline No (formal) education & Ref. & Ref. \\
\hline Primary (grade 1-5) & $1.36(1.05 \text { to } 1.76)^{\star}$ & $1.05(0.80$ to 1.39$)$ \\
\hline Secondary (grade 6-10) & $1.97(1.56 \text { to } 2.48)^{\star \star \star}$ & $1.30(1.00 \text { to } 1.68)^{*}$ \\
\hline \multicolumn{3}{|l|}{ Media exposure } \\
\hline Hindu & $2.03(1.33 \text { to } 3.11)^{\star \star \star}$ & $1.82(1.20 \text { to } 2.77)^{\star \star}$ \\
\hline \multicolumn{3}{|l|}{ Ethnic group } \\
\hline Brahmin, Chhetri and Madhesi & Ref. & Ref. \\
\hline Janajati and Newar (Mountain Hill and Terai) & $0.77(0.60 \text { to } 0.99)^{*}$ & $0.85(0.65$ to 1.11$)$ \\
\hline Dalit (Mountain Hill and Terai) and Muslim & $0.47(0.33 \text { to } 0.67)^{\star \star \star}$ & $0.66(0.47 \text { to } 0.94)^{\star}$ \\
\hline Others & $0.77(0.43$ to 1.36$)$ & $0.60(0.34$ to 1.05$)$ \\
\hline \multicolumn{3}{|l|}{ Alcohol consumption } \\
\hline No & Ref. & Ref. \\
\hline Yes & $1.01(0.83$ to 1.23$)$ & $0.92(0.72$ to 1.17$)$ \\
\hline \multicolumn{3}{|l|}{ Current smoker } \\
\hline No & Ref. & \\
\hline Yes & $1.15(0.90$ to 1.48$)$ & $1.42(1.04 \text { to } 1.94)^{*}$ \\
\hline \multicolumn{3}{|l|}{ Functional disability } \\
\hline No & Ref. & \\
\hline Yes & 1.35 (0.85 to 2.14$)$ & $1.40(0.86$ to 2.29$)$ \\
\hline \multicolumn{3}{|l|}{ Province } \\
\hline Province 1 & Ref. & Ref. \\
\hline
\end{tabular}


Table 2 Continued

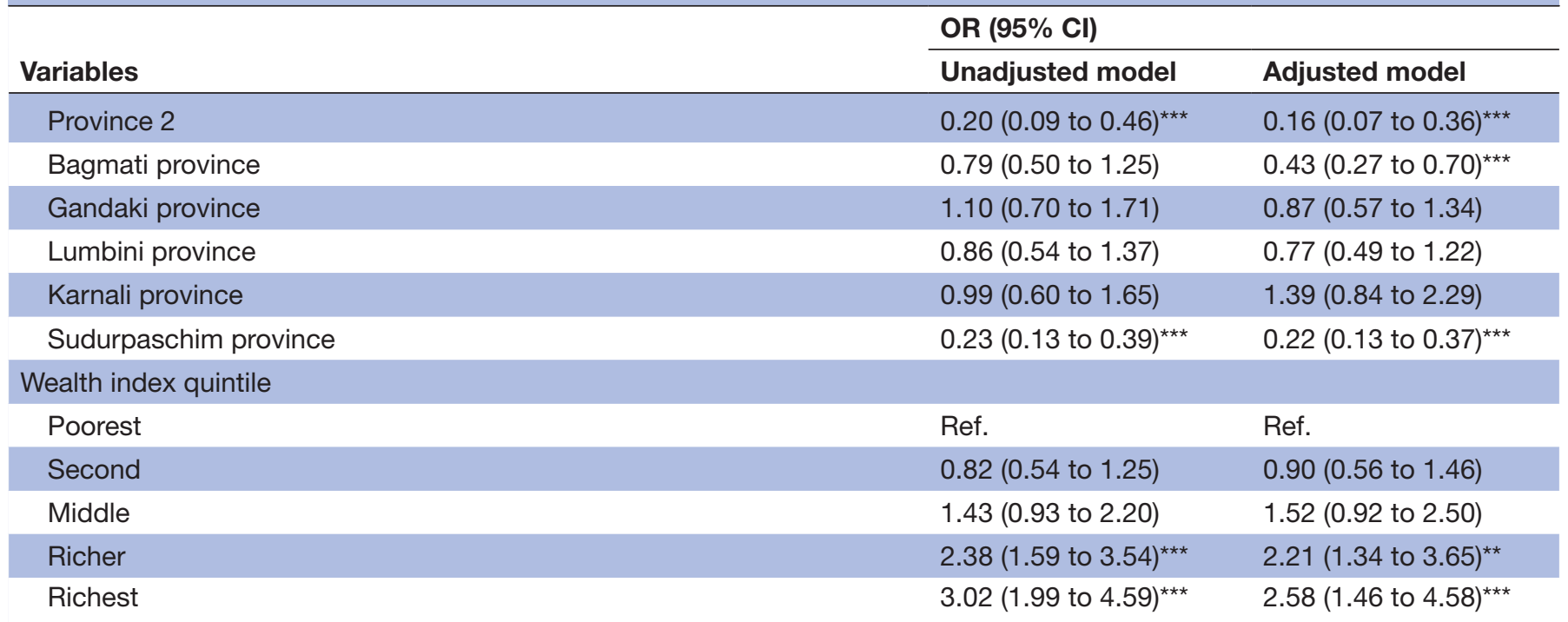

${ }^{*} \mathrm{P} \leq 0.05,{ }^{* *} \mathrm{p} \leq 0.01,{ }^{* * *} \mathrm{p} \leq 0.001$.

compared with province 1 (reference). Households from province 2, Bagmati province and Sudurpaschim province were $84 \%, 57 \%$ and $78 \%$ less likely to have health insurance membership compared with the households from province 1, respectively. Similarly, wealth status of households was a significant predictor of health insurance enrolment; households belonging to richer and richest wealth quintiles were more than two times to nearly two and half times more likely to have health insurance membership in comparison to the ones from the poorest wealth quintile.

\section{Results from the measures of inequality}

Figure 1 exhibits the inequality in health insurance enrolment by wealth status. Since the concentration curve is below the line of equality, the health insurance enrolment was disproportionately higher among wealthy

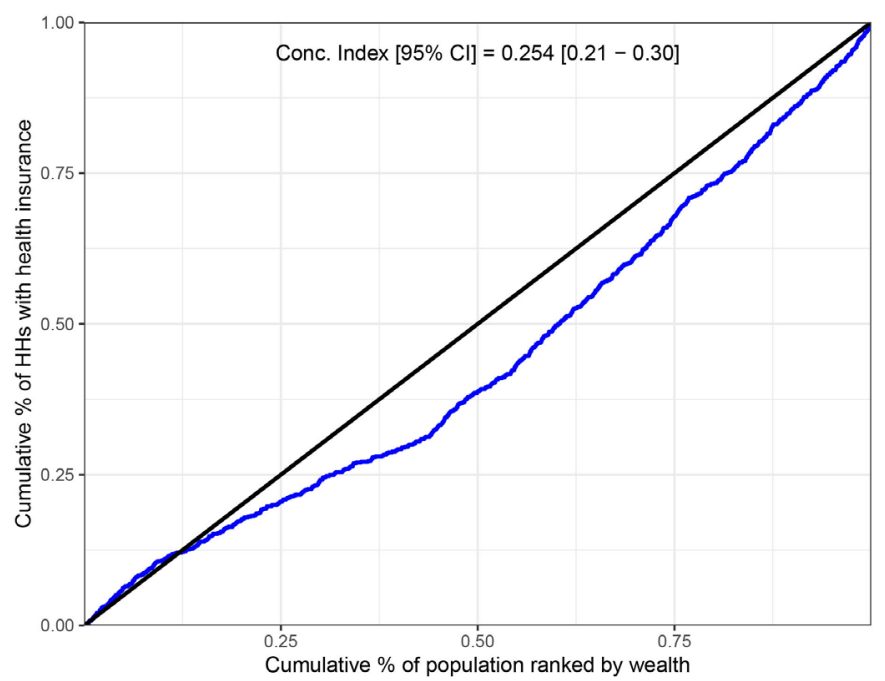

Figure 1 Concentration curve showing wealth-related inequality in health insurance enrolment. households. Also, a positive estimated concentration index $(0.25 ; 95 \%$ CI 0.21 to $0.30 ; \mathrm{p}<0.001)$ means the health insurance enrolment was concentrated among the wealthier households in comparison to poor households.

\section{Decomposition of the concentration index}

Table 3 presents the decomposition of the concentration index used to explain the source of wealth-related inequality in health insurance enrolment. The major contribution to the inequality was from the education level of household head, followed by media exposure, area of residence and province. The residual contribution is 0.09 , which represents the amount of wealth-related inequality not explained by the household characteristics.

\section{DISCUSSION}

This study aimed to understand the factors that influence the decision of households to get enroled in health insurance schemes in Nepal. We analysed the odds of being enroled in health insurance schemes with respect to various socioeconomic, demographic and lifestyle-related characteristics of households available from nationally representative MICS 2019. We found that level of education of household head; exposure to mass media in the family; ethnicity; religion; smoking habit of the family member; province and wealth quintile are associated with the decision made by families to enrol into health insurance schemes. Further, we measured the wealth-related inequality in terms of concentration index for health insurance enrolment and examined the determinants of inequality. We found that health insurance enrolment was disproportionately higher among wealthy households and the decomposition of the concentration index showed that the observed wealth-related inequality was 
Table 3 Decomposition of the concentration index

\begin{tabular}{llll}
\hline Variables & Elasticity & Concentration index & Contribution (\%) \\
\hline Area of residence (urban) & 0.346 & 0.069 & $0.024(9.44)$ \\
Ethnic group (Brahmin, Chhetri, Madhesi, Janajati and Newar) & 0.124 & 0.030 & $0.004(1.44)$ \\
Religion & 0.425 & 0.006 & $0.003(1.10)$ \\
Media exposure & 0.482 & 0.093 & $0.045(17.74)$ \\
Low HDI province (province 2 and Karnali) & 0.345 & 0.046 & $0.016(6.23)$ \\
Household head education & 0.348 & 0.195 & $0.068(26.70)$ \\
Residual & & & $0.09(37.37)$ \\
Total & & & $0.25(100)$ \\
\hline
\end{tabular}

HDI, Human Development Index.

explained mostly by education level of household head, media exposure, urban residence and province.

Households with educated head were more likely to have health insurance membership compared with households without formally educated head. Odds of getting enroled into the scheme increased with an increase in level of education. Our finding is consistent with similar studies conducted in Nepal, ${ }^{28}{ }^{42}$ Ghana, ${ }^{72}{ }^{43}$ Bangladesh ${ }^{30}$ Kenya $^{31}$ and Burkina Faso. ${ }^{44}$ This result could be attributed to the fact that educated households head have a better understanding of financial risks associated with sudden health shock compared with not educated households head and they can make informed decision about getting enroled into the schemes. ${ }^{72} 30$ Similarly, households with members exposed to mass media (radio or TV or magazine) had significantly better probability of being enroled into the schemes compared with their counterparts. This finding is similar to the observation made by previous study conducted in Baglung and Kailali districts of Nepal that reported a significant difference in terms of health insurance enrolment between groups based on access to health insurance messages through radio and $T V{ }^{45}$ This association may be due to the fact that households with members exposed to mass media have better access to the information regarding the enrolment process and future benefits the membership offers in terms of financial risk protection. ${ }^{45}$

In Nepal, Brahmin, Chhetri, Madhesi, Janajati and Newar are considered upper and privileged caste in comparison Dalits and other ethnic minorities. Hindu and households from advantaged ethnic group were more likely to be registered with the health insurance schemes compared with non-Hindus and Dalits (including Muslims and ethnic minorities). This finding is consistent with the findings from studies conducted in Palpa and Kailali of Nepal which reported the increased likelihood of privileged ethnic group to be enroled in the health insurance scheme compared with their underprivileged counterparts. ${ }^{28} 42$

Households from province 2, Bagmati province and Sudurpaschim province were less likely to have health insurance membership compared with the households from province 1 . Both province 2 (southern plain districts) and Sudurpaschim (far-west districts) are relatively backward provinces in terms of overall socioeconomic development and are generally lagging in terms of other public health coverage indicators as well. ${ }^{46}$ Regarding Bagmati province (central districts with capital Kathmandu), which is comprised of comparatively more urban settlements compared with all other provinces, further investigation may be needed whether the urbanisation can explain lower odds of enrolment compared with province 1 since the association between area (rural/urban) and health insurance enrolment is found be mixed in various studies (discussed below). Geographical disparity in terms of coverage of health insurance is observed in other LMICs as well. Difficult geographical terrain, low overall socio-economic development, lack of access to quality services, lack of awareness and inability to take health decisions are some of the reasons identified in these studies.

Moreover, as found in previous studies from LMICs, including Nepal, wealth status of households was found to be a significant predictor of health insurance enrolment. ${ }^{28} 2932334243$ Households belonging to the wealthiest quintiles (richer and richest wealth quintiles) were nearly two to two and half times more likely to have health insurance membership compared with the households from poorest quintiles. This result could be attributed to the fact as the households get richer, their ability to allocate money for health insurance premium increases. The findings from measure of inequality using concentration curve and index also showed that the enrolment of health insurance was more concentrated among wealthier households. This means the wealthier were more likely to be protected from financial risk while poor were exposed to potential financial hardships owing to OOP payments for healthcare. Inequality in coverage of health insurance is a challenge for many countries. Studies conducted in Ghana and China using concentration curves and indexes showed that the health insurance coverage was more concentrated among wealthy households. ${ }^{32} 47$ Study from the Philippines showed that as the overall coverage of health insurance increased over 2003-2017, 
the inequality between wealth groups decreased, evident from the decreased concentration index from 0.3000 in 2003 to 0.0247 in $2017 .^{48}$ The study from the Philippines also showed that the increased health insurance coverage over years was associated with the reduced socio-economic inequality in healthcare utilisation.

Few variables that did not demonstrate a significant association with the health insurance enrolment in our study have conflicting findings in other studies. For example, some studies ${ }^{7} 490$ indicated lower enrolment among female-headed households and others ${ }^{28} 293451$ reported to have no significant association and even others ${ }^{5253}$ found the opposite to be true. Salari $e t a t^{29}$ found no significant association between area (household belonging to urban or rural setting) and health insurance enrolment while reporting the findings from Ghana Demography and Health Survey 2014 and Ghana Living Standard Survey 2012/2013, however, inverse relation was obtained from Ghana MICS 2011. Negative relation between being a household from urban area and health insurance enrolment was also reported by Jehu-Appiah $e t a l^{7}$ and Dake. ${ }^{32}$ Study conducted in Kailali district of Nepal, however, found no significant association between being a household from urban area and having a health insurance membership. ${ }^{28}$ Contrasting finding was also reported with regards to the association between family size and odds of health insurance enrolment. Previous study from Nepal has reported that households with more than four family members (but less than eight members) are more likely to enrol in health insurance. ${ }^{28}$ However, few studies have reported no significant association between the family size and odds of enrolment. ${ }^{3042} 43$ Our finding corroborates with the study from Bangladesh ${ }^{30}$ that there is no significant association between households having under-five children and increased odds of enrolment. In contrast, Salari $e t a l^{29}$ based on the analysis of nationally representative household surveys of Ghana, have found significant association. Additional studies may be required to ascertain the relationship of these variables with health insurance enrolment.

\section{Strength of this study}

The study is based on nationally representative household survey and provides a baseline scenario for recently launched contribution-based risk pooling arrangement through HIB and SSF. The results will potentially serve as a baseline for future analysis of national-level surveys (such as next round of MICS) that collect health insurance relevant data and will thus allow examining the changes over time.

\section{Limitations}

The list of determinants of health insurance enrolment included in this study is not an exhaustive one. The potential determinants such as occupation of household head, recent illness in family, presence of chronic diseases in any family member, availability and quality of health services could not be included in this analysis due to unavailability of such data in this round of MICS. Since the analysis is based on cross-sectional data, we could not establish any causal relationship between the variables under study and health insurance enrolment. Due to the low coverage of different health insurance schemes (such as community-based health insurance, private health insurance), we could not present the result for individual health insurance type. From the start of NHI implementation, the GoN has made policy provision to subsidise the premium of indigents and other targeted households, however, tracking those households was not possible from this survey. Notwithstanding, this study has been able to include possible policy-relevant variables and analyse their influence on uptake decision of health insurance. We believe this will be useful for policymakers and planners involved in coverage expansion of recently launched health insurance schemes in Nepal.

\section{Conclusion}

We found education of household head; exposure to mass media; religious and ethnic background; current smoking; geographical location (province) and wealth status as important predictors of health insurance enrolment in Nepal. We observed significant wealth-related inequality in health insurance affiliation. The wealthrelated inequality was mainly explained by observed disparities in education, media exposure and other background characteristics of households such as geographical location, religious belief and ethnicity. Our study has provided the gap and disparities in health insurance enrolment that could be useful to policy-makers to formulate targeted strategies to reach population subgroup (uneducated household, disadvantaged ethnic and religious groups, households from backward geographical regions, household not having access to mass media) that are at risk of lagging in terms of affiliation with risk pooling arrangements. Without a special focus on these groups achieving equality and universality in health, the key for moving towards UHC, may not be possible. The study recommends regular monitoring of inequality in health insurance enrolment across demographic and socioeconomic groups.

Twitter Vishnu Prasad Sapkota @VishnuP04087498

Acknowledgements The authors would like to acknowledge the Multiple Indicator Cluster Surveys (MICS) for permitting us to access and use the dataset for this study.

Contributors UPB and VPS conceptualised and designed the study, performed literature review, did statistical analysis and wrote the draft. Both authors revised the draft and approved the final manuscript. UPB accepts full responsibility of the study, has access to the data, and controlled the decision to publish.

Funding The authors have not declared a specific grant for this research from any funding agency in the public, commercial or not-for-profit sectors.

Competing interests None declared.

Patient and public involvement Patients and/or the public were not involved in the design, or conduct, or reporting, or dissemination plans of this research.

Patient consent for publication Not applicable.

Ethics approval The analysis was based on publicly available MICS6 datasets. The permission to access and use these datasets for this study purpose was obtained 
from UNICEF/MICS website (http://mics.unicef.org/surveys), so no further ethical approval was necessary. The protocol for the survey was approved by the Central Bureau of Statistics (CBS) as per the Statistical Act (1958) in September 2018. Verbal consent was obtained from each respondent after a thorough introduction of the survey. All respondents were briefed about the voluntary nature of participation. Participants were assured that the information they share during the interview will be kept confidential and anonymous.

Provenance and peer review Not commissioned; externally peer reviewed.

Data availability statement Data are available upon reasonable request. Data are available in a public, open access repository. We used publicly available data and it is accessible from the MICS website (https://mics.unicef.org/surveys) on the request.

Open access This is an open access article distributed in accordance with the Creative Commons Attribution Non Commercial (CC BY-NC 4.0) license, which permits others to distribute, remix, adapt, build upon this work non-commercially, and license their derivative works on different terms, provided the original work is properly cited, appropriate credit is given, any changes made indicated, and the use is non-commercial. See: http://creativecommons.org/licenses/by-nc/4.0/.

\section{ORCID iDs}

Umesh Prasad Bhusal http://orcid.org/0000-0001-9331-6028

Vishnu Prasad Sapkota http://orcid.org/0000-0002-4014-8267

\section{REFERENCES}

1 United Nations. Transforming our world: the 2030 agenda for sustainable development. Department of Economic and Social Affairs. United Nations Gen Assem, 2015. https://sdgs.un.org/ 2030agenda

2 WHO. The world health report 2010-health systems financing: the path to universal coverage 2010.

3 Mathauer I, Saksena P, Kutzin J. Pooling arrangements in health financing systems: a proposed classification. Int J Equity Health 2019;18:1-11.

4 WHO. Social health insurance: sustainable health financing, universa coverage and social health Insurance- report by the Secretariat 2005.

5 Hsiao WC, Shaw RP. Social health insurance for developing nations. WBI development studies, 2007. Available: https://openknowledge. worldbank.org/handle/10986/6860

6 Liu X, Tang S, Yu B, et al. Can rural health insurance improve equity in health care utilization? A comparison between China and Vietnam. Int J Equity Health 2012;11:10-19.

7 Jehu-Appiah C, Aryeetey G, Spaan E, et al. Equity aspects of the National health insurance scheme in Ghana: who is enrolling, who is not and why? Soc Sci Med 2011;72:157-65.

8 Carrin G, James C. Reaching Universal Coverage via social health insurance: key design features in the transition period discussion paper 2004.

9 Universal Health Coverage. Available: https://www.who.int/healthtopics/universal-health-coverage\#tab=tab_1 [Accessed 1 Mar 2021].

10 MoHP. Nepal National Health Accounts 2016/17, Ministry of Health and Population, Government of Nepal, Kathmandu, Nepal 2019.

11 Wang H, Torres LV, Travis P. Financial protection analysis in eight countries in the who south-east Asia region. Bull World Health Organ 2018;96:610-20.

12 Pokharel R, Silwal PR. Social health insurance in Nepal: a health system departure toward the universal health coverage. Int $\mathrm{J}$ Health Plann Manage 2018;33:573-80.

13 Mishra SR, Khanal P, Karki DK, et al. National health insurance policy in Nepal: challenges for implementation. Glob Health Action 2015;8:28763.

14 Ministry of Health and Population. Female community health programme, 2020. Available: https://www.mohp.gov.np/eng/ program/reproductive-maternal-health/female-community-healthprogramme [Accessed 10 Sep 2021].

15 Gaihre RH. 2020 Asia-Pacific Statistics Week Identification of Poor Households for Targeting in Nepal 2020.

16 AusAID. Targeting the poorest: an assessment of the proxy means test methodology. Available: www.ausaid.gov.au [Accessed 11 Sep 2021].

17 Progress of the health and population sector, 2019/2020: national joint annual review report 2020.

18 Ranabhat CL, Subedi R, Karn S. Status and determinants of enrollment and dropout of health insurance in Nepal: an explorative study. Cost Eff Resour Alloc 2020;18:1-13.
19 Social Security Fund. Available: https://ssf.gov.np/np/ dailysummarreport.html [Accessed 2 Mar 2021].

20 Central Bureau of Statistics. Nepal multiple indicator cluster survey 2019, survey findings report. Kathmandu, Nepal: Central Bureau of Statistics and UNICEF Nepal, 2020. Available: http://www.unicef.org/ statistics/index_24302.htm

21 Khan S, Hancioglu A. Multiple indicator cluster surveys: delivering robust data on children and women across the globe. Stud Fam Plann 2019;50:279-86.

22 Central Bureau of Statistics (CBS). Population monograph of Nepal, Volume II (social demography) 2014.

23 Rezayatmand R, Groot W, Pavlova M. Smoking behaviour and health care costs coverage: a European cross-country comparison. Int J Health Econ Manag 2017;17:453-71.

24 Doiron D, Jones G, Savage E. Healthy, wealthy and insured? The role of self-assessed health in the demand for private health insurance. Health Econ 2008;17:317-34.

25 Sumarto S, Suryadarma D, Suryahadi A. Predicting consumption poverty using non-consumption indicators: experiments using Indonesian data. Soc Indic Res 2007;81:543-78.

26 Johnston R, Jones K, Manley D. Confounding and collinearity in regression analysis: a cautionary tale and an alternative procedure, illustrated by studies of British voting behaviour. Qual Quant 2018;52:1957-76.

27 Ghimire P, Sapkota VP, Poudyal AK. Factors associated with enrolment of households in Nepal's National Health Insurance Program. Int J Health Policy Manag 2019;8:636-45.

28 Paudel DR. Factors affecting enrollment in government health insurance program in Kailali district. $J$ Nepal Health Res Counc 2019;17:388-93

29 Salari P, Akweongo P, Aikins M, et al. Determinants of health insurance enrolment in Ghana: evidence from three national household surveys. Health Policy Plan 2019;34:582-94.

30 Mahmood SS, Hanifi SMA, Mia MN, et al. Who enrols in voluntary micro health insurance schemes in low-resource settings? Experience from a rural area in Bangladesh. Glob Health Action 2018;11:1525039.

31 Kimani JK, Ettarh R, Warren C, et al. Determinants of health insurance ownership among women in Kenya: evidence from the 2008-09 Kenya demographic and health survey. Int J Equity Health 2014;13:27

32 Dake FAA. Examining equity in health insurance coverage: an analysis of Ghana's National Health Insurance Scheme. Int J Equity Health 2018;17:1-10.

33 Mathauer I, Schmidt J-O, Wenyaa M. Extending social health insurance to the informal sector in Kenya. An assessment of factors affecting demand. Int $J$ Health Plann Manage 2008;23:51-68.

34 Kapologwe NA, Kagaruki GB, Kalolo A, et al. Barriers and facilitators to enrollment and re-enrollment into the community health funds/ Tiba Kwa Kadi (CHF/TIKA) in Tanzania: a cross-sectional inquiry on the effects of socio-demographic factors and social marketing strategies. BMC Health Serv Res 2017;17:1-9.

35 StataCorp. Stata statistical software: release 16. College Station, TX: StataCorp LLC, 2019.

36 Kawachi I, Subramanian SV, Almeida-Filho N. A glossary for health inequalities. J Epidemiol Community Health 2002;56:647-52.

37 Starfield B. Improving equity in health: a research agenda. Int $J$ Health Serv 2001;31:545-66.

38 Bergen N, Ruckert A, Abebe L, et al. Characterizing 'health equity' as a national health sector priority for maternal, newborn, and child health in Ethiopia. Glob Health Action 2021;14:1853386.

39 O'Donnell O, van Doorslaer E, Wagstaff A. Analyzing health equity using household survey data. World Bank Group, 2007.

40 Wickham H. ggplot2: elegant graphics for data analysis. New York: Springer-Verlag, 2009.

41 R Core Team. R: a language and environment for statistical computing. R foundation for statistical computing, Vienna, Austria, 2017. Available: https://www.R-project.org/

42 Ghimire P, Sapkota VP, Poudyal AK. Factors associated with enrolment of households in nepal's national health insurance program. Int J Health Policy Manag 2019;8:636-45.

43 Kwarteng A, Akazili J, Welaga P. The state of enrollment on the National health insurance scheme in rural Ghana after eight years of implementation. Int J Equity Health 2019;19:1-14.

44 De Allegri M, Kouyaté B, Becher $\mathrm{H}$, et al. Understanding enrolment in community health insurance in sub-Saharan Africa: a populationbased case-control study in rural Burkina Faso. Bull World Health Organ 2006;84:852-8

45 Acharya D, Devkota B, Gautam K, et al. Association of information, education, and communication with enrolment in health insurance: a case of Nepal. Arch Public Health 2020;78:1-13. 
46 Sapkota VP, Bhusal UP, Acharya K. Trends in national and subnational wealth related inequalities in use of maternal health care services in Nepal: an analysis using demographic and health surveys (2001-2016). BMC Public Health 2021;21:1-14.

47 Liu J, Shi L, Meng Q, et al. Income-related inequality in health insurance coverage: analysis of China health and nutrition survey of 2006 and 2009. Int J Equity Health 2012;11:1-11.

48 Siongco KLL, Nakamura K, Seino K. Reduction in inequalities in health insurance coverage and healthcare utilization among older adults in the Philippines after mandatory National health insurance coverage: trend analysis for 2003-2017. Environ Health Prev Med 2020;25:17.

49 Kusi A, Enemark U, Hansen KS, et al. Refusal to enrol in Ghana's National health insurance scheme: is affordability the problem? Int $J$ Equity Health 2015;14:2.
50 Adhikari N, Wagle RR, Adhikari DR, et al. Factors affecting Enrolment in the community based health insurance scheme of Chandranigahapur hospital of Rautahat district. J Nepal Health Res Counc 2019;16:378-84.

51 Acharya D, Devkota B, Wagle BP. Factors associated to the enrollment in health insurance: an experience from selected districts of Nepal. Asian Soc Sci 2019;15:90.

52 Alatinga KA, Williams JJ. Towards universal health coverage: exploring the determinants of household Enrolment into National health insurance in the Kassena Nankana District, Ghana. Ghana J Dev Stud 2015;12:88.

53 Dong H, Kouyate B, Cairns J, et al. Differential willingness of household heads to pay community-based health insurance premia for themselves and other household members. Health Policy Plan 2004;19:120-6. 